\title{
Deposits of terminal complement complex (TCC) in muscularis mucosae and submucosal vessels in ulcerative colitis and Crohn's disease of the colon
}

\author{
T S HALSTENSEN, T E MOLLNES, O FAUSA AND P BRANDTZAEG
}

From the Laboratory for Immunohistochemistry and Immunopathology (LIIPAT), Institute of Pathology, Institute of Immunology and Rheumatology, and Section of Gastroenterology, Medical Department A, University of Oslo, The National Hospital, Rikshospitalet, Oslo, Norway

SUMmary Extensively washed, ethanol fixed and paraffin embedded colonic specimens from 15 patients with ulcerative colitis (UC) and nine patients with Crohn's disease (CD) of the colon, ileal specimens from six patients with $\mathrm{CD}$ of the ileum, and histologically normal control specimens obtained from 10 patients operated for colonic carcinoma, were examined by immunohistochemistry with a monoclonal antibody specific for a neoepitope in the $\mathrm{C} 9$ part of the terminal complement complex (TCC). The submucosal blood vessels in inflammatory bowel disease (IBD) showed significantly more TCC positivity than the controls, and vascular TCC deposition was statistically related $(p<0.001)$ to degree of inflammation. Five of the six ileal $C D$ specimens contained likewise vascular TCC deposits. In addition, five UC specimens and one colonic CD specimen contained TCC-positive fibrils in the muscularis mucosae or submucosa. There was no significant difference in vascular TCC deposits between $U C$ and $C D$. The results suggested that terminal complement activation takes place in the intestinal lesions of IBD.

The aetiology of inflammatory bowel disease (IBD) is unknown. Several possibilities have been suggested, including infectious agents, autoimmunity and local immune complex deposition. '2 Despite the lack of definite evidence, it is generally believed that immunological mechanisms contribute to the pathogenesis of ulcerative colitis (UC) and Crohn's disease (CD). Immunohistochemical studies of diseased mucosa have revealed a marked local over production of IgG in IBD ${ }^{3}$ with a significantly higher IgG1to-IgG2 proportion in $\mathrm{UC}$ than in $\mathrm{CD} .{ }^{+}$To some extent the locally produced IgG shows specificity for intestinal microorganisms. ${ }^{5-7}$ Moreover, local IgG has been found to react with an intestinal epithelial antigen in UC but not in CD. ${ }^{8}$

As IgG can activate complement, the striking local IgG response seen in IBD is of considerable pathogenetic interest. In 1974 Ballard and Shiner" proposed that immune complexes formed at the epithelial basement membrane might activate complement and attract polymorphonuclear cells;

Address for correspondence: T S Halstensen, L.IIPAT. Rikshospitalet, N-(O)28 Oslo 1. Norway.

Accepted for publication 1 September 1988. the release of proteolytic enzymes from these cells could then lead to epithelial destruction.

Immune complexes induce $\mathrm{C} 3$ activation either by the classical or alternative pathway. $\mathrm{C} 3 \mathrm{~b}$ participates in the $\mathrm{C} 5$ convertase which initiates the terminal pathway when $\mathrm{C} 5$ is cleaved. The terminal complement complex (TCC) is formed when $\mathrm{C} 5$ b reacts with C6, C7, C8, and C9.

On biological membranes TCC appears in the form of the cytolytic, pore forming C $5 b-9(m)$." In a fluid phase, however, S-protein (vitronectin) binds to C5b-7 and the non-cytolytic soluble form of TCC (SC5b-9) is formed." Both C5b-9(m) and SC5b-9 express TCC neoepitopes which are absent from the native components. The purpose of this study was to examine lesions of IBD for the expression of TCC neoepitope suggestive of local complement activation.

\section{Methods}

TISSUE SPECIMENS

Colonic tissue from inflamed lesions were obtained immediately after surgical resection in 15 patients 
Table 1 Clinical information about patients with IBI) and TC 'deposits in their colonic specimens

\begin{tabular}{|c|c|c|c|c|c|c|c|c|c|c|c|}
\hline \multirow{2}{*}{$\begin{array}{l}\text { Patient } \\
\text { no }\end{array}$} & \multirow{2}{*}{$\begin{array}{l}\text { Age } \\
\text { (yrs) }\end{array}$} & \multirow[b]{2}{*}{ Sex } & \multirow[b]{2}{*}{ Diagnosis } & \multicolumn{2}{|c|}{ Medication } & \multirow{2}{*}{$\begin{array}{l}\text { Topographic } \\
\text { affection }\end{array}$} & \multirow{2}{*}{$\begin{array}{l}\text { Dise'ase' } \\
\text { duration }\end{array}$} & \multirow{2}{*}{$\begin{array}{l}\text { Specimen } \\
\text { site }\end{array}$} & \multirow{2}{*}{$\begin{array}{l}\text { local } \\
\text { inflam. }\end{array}$} & \multirow{2}{*}{$\begin{array}{l}\text { lascular } \\
\text { TCe }\end{array}$} & \multirow{2}{*}{$\begin{array}{l}\text { Fibrillan } \\
\text { TC ' }\end{array}$} \\
\hline & & & & Pred & Sala. & & & & & & \\
\hline 1 & 33 & $\mathrm{~F}$ & UC & No & Yes & Total & 9 years & Sigmoidium & + & $++1++$ & 0 \\
\hline 2 & 34 & $\mathrm{~F}$ & $\mathrm{UC}$ & UN & UN & Total & 5 years & Sigmoidium & +++ & $+++1++$ & () \\
\hline 3 & 39 & $\mathrm{~F}$ & UC & Yes & Yes & Total & 9 years & Sigmoidium & $+t+$ & $++t+t+$ & () \\
\hline 4 & 27 & $\mathbf{M}$ & UC & No & Yes & Total & 10 years & Transversum & +++ & $+t+1+t+$ & $+t+$ \\
\hline 6 & 33 & $\mathrm{M}$ & $\mathrm{UC}$ & Yes & Yes & UN & UN & Rectum & $+t+$ & $++t+t+$ & $t+$ \\
\hline 7 & 29 & $\mathrm{~F}$ & UC & Yes & No & Total & 24 years & Ascendens & $++t$ & $+++1+++$ & $t+t$ \\
\hline 8 & 17 & $\mathrm{~F}$ & UC & No & Yes & Total & 3 years & Ascendens & ++ & $++1+t+$ & + \\
\hline 9 & 47 & $\mathrm{M}$ & UC & Yes & Yes & Total & 1 year & Rectum & ++ & $++1++$ & $+t$ \\
\hline 10 & 26 & $\mathrm{~F}$ & UC & No & Yes & Total & 9 years & Sigmoidium & $++t$ & $+++1+++$ & 0 \\
\hline 11 & 20 & $\mathrm{~F}$ & UC & No & Yes & Total & 6 years & Ascendens & ++ & $+1+$ & 0 \\
\hline 12 & 43 & $\mathrm{~F}$ & UC & Yes & Yes & UN & 17 years & Descendens & $+t$ & $(0 /()$ & 0 \\
\hline 13 & 28 & $\mathrm{~F}$ & UC & No & No & Total & 1 year & Ascendens & +++ & $+++1++$ & 0 \\
\hline 15 & 44 & $F$ & UC & Yes & Yes & Total & UN & Sigmoidium & ++ & $++1+$ & 0 \\
\hline 16 & 23 & $\mathrm{~F}$ & $C D$ & Yes & No & Seg. & UN & Transversum & + & $+1++$ & 0 \\
\hline 17 & 20 & $\mathrm{M}$ & CD & Yes & Yes & Seg. & UN & Transversum & +++ & $+++1++$ & 0 \\
\hline 18 & 64 & $\mathrm{~F}$ & CD & UN & UN & Total & UN & Transversum & +++ & $+++1+++$ & ++ \\
\hline 19 & 36 & $\mathrm{M}$ & CD & UN & No & Seg. & UN & Sigmoidium & +++ & $++1++$ & () \\
\hline 20 & 30 & $\mathrm{~F}$ & CD & Yes & No & Total & UN & Rectum & ++ & $0 /(0$ & () \\
\hline 21 & 27 & $F$ & $C D$ & Yes & No & Total & 2 years & Transversum & ++ & $+1++$ & () \\
\hline 22 & 35 & $\mathrm{~F}$ & $\mathrm{CD}$ & Yes & No & UN & UN & Sigmoidium & ++ & $+++1+++$ & () \\
\hline 23 & 15 & $\mathrm{M}$ & $\mathrm{CD}$ & No & No & Seg. & 3 years & Rectum & + & $++1++$ & 0 \\
\hline 24 & 18 & $\mathbf{M}$ & $C D$ & No & No & Seg. & 1 year & Ascendens & ++ & $+1+$ & 0 \\
\hline
\end{tabular}

Pat. = patient Pred. $=$ prednisolone: Sala. $=$ salazopyrin: $\mathrm{UC}=$ ulcerative colitis: $\mathrm{UN}=$ unknown: $\mathrm{CD}=\mathrm{Crohn}$ 's disease of the colon: Seg. $=$ segmental. ${ }^{*}$ The vascular TCC score from two blind examinations.

with UC (average age, 33 years; range, 17-50) and nine with $\mathrm{CD}$ of the colon (average age, 30 years; range, 15-64, Table 1). In addition, we collected ileal samples from six patients with $\mathrm{CD}$ of the ileum (average age, 31 years; range, 18-43). The diagnoses were based on clinical and pathological criteria. Control material was obtained from histologically normal mucosa of 10 patients (average age, 71 years; range, 51-80) undergoing colonic resection because of carcinoma. These specimens were taken well away from the tumour.

All specimens were collected in ice cold isotonic saline and brought to the laboratory within one hour. Thin tissue slices were washed for $48 \mathrm{~h}$ at $4^{\circ} \mathrm{C}$ in $0.01 \mathrm{M}$ phosphate buffer ( $\mathrm{pH} 7.5$ ) containing $0.15 \mathrm{M}$ $\mathrm{NaCl}$ (PBS) to remove diffusible proteins. Thereafter the tissue was fixed for $18 \mathrm{~h}$ in cold $96 \%$ ethanol, dehydrated in absolute ethanol, cleared in xylene and embedded in paraffin for three to four hours at $56^{\circ} \mathrm{C}$. ${ }^{12}$ The paraffin blocks were stored at $4^{\circ} \mathrm{C}$ until used.

\section{IMMUNOHISTOCHEMISTRY}

Dewaxed tissue sections $(6 \mu \mathrm{m})$ were incubated for 30 minutes at room temperature with ascitic fluid of a murine monoclonal antibody (MoAb) to a C9 neoepitope of TCC.13 The reagent (aE11) was applied at an $\mathrm{IgG}$ concentration of $2.5 \mathrm{mg} / \mathrm{ml}(1: 40)()$ dilution in PBS containing bovine serum albumin at $125 \mathrm{~g} / \mathrm{l})$. Rabbit antimouse IgG conjugated with fluorescein isothiocynate (molar $\mathrm{F} / \mathrm{P}$ ratio $=1 \cdot 2$ ) was used at $0.46 \mathrm{~g} / \mathrm{l}$ for $30 \mathrm{~min}$ in an indirect immunofluorescence technique. In addition, the alkaline phosphatase antialkaline phosphatase (APAAP) method was used as detailed elsewhere ${ }^{14}$ to examine selected specimens.

\section{MICROSCOPY AND PHOTOGRAPHY}

Immunofluorescence features were observed in a Leitz Orthoplan microscope equipped with an XBO $150 \mathrm{~W}$ lamp. The results were recorded on Agfa 1000) ASA daylight film.

\section{IMMUNOHISTOCHI:MICAL IEVALUATION}

The immunofluorescence examination was performed blindly twice by the same investigator. Each specimen was given a semi-quantitative score ranging from quite faint fluorescence in a few submucosal vessels (0) to intense staining in many vessels through the submucosa $(+++)$. One tissue section from each immunohistochemical series was stained with haematoxylin and cosin and was examined blindly. 


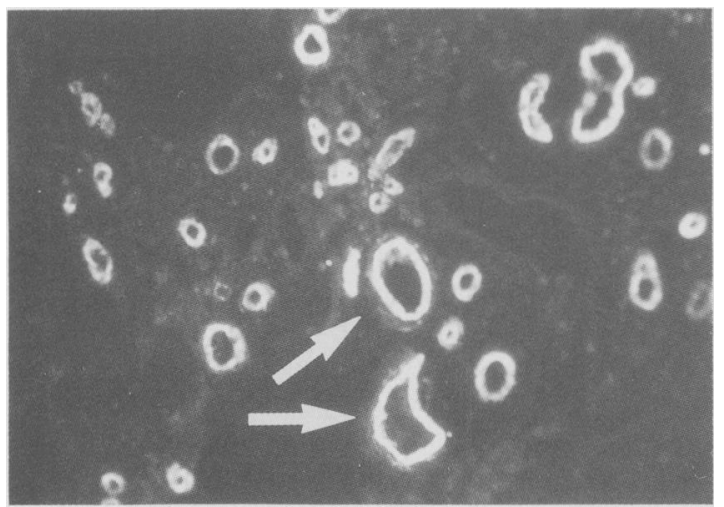

Fig. 1 Staining for the TCC neopitope in washed ethanolfixed paraffin embedded colonic specimens from a patient with ulcerative colitis. Intense fluorescence staining was observed in the submucosal vessel walls (arrows). (Magnification $\times 44$ ).

Each specimen was given a semiquantitative inflammatory score from negative $(0)$ to intense $(+++)$ on the basis of the cellular infiltrate density.

\section{CONTROI.S}

Incubation with murine control ascites at a dilution comparable to that used for the MoAb (1:4000), did not produce detectable staining. Occasional weak autofluorescence was seen, however, in the internal elastic membrane of some vessels.

STATISTICAI. ANALYSIS

Comparisons between specimen categories were based on the Mann-Whitney non-parametric twotailed test. Correlation analyses were performed by the Kendall's $t$ test.

\section{Results}

Intense staining for TCC in submucosal blood vessels was found by indirect immunofluorescence in 14 of 15 UC specimens and in eight of nine colonic $C D$ specimens (Fig. 1 and Table 1). Five of six ileal CD specimens were likewise positive for TCC (Table 2). By contrast, only one of 10 histologically normal colonic control specimens showed positive vascular staining for TCC $(\mathrm{p}<0.01) \quad$ (Table 3). Reexamination with the sensitive APAAP method, however, revealed some deposits in occasional submucosal vessels in every control specimens.

The staining intensity of individual vessel walls and the number of positive vessels varied considerably in the inflamed specimens. Nevertheless the TCC positivity scores obtained from the two blind examinations were well correlated $(\mathrm{t}=7.7 ; \mathrm{p}<0.001)$. Furthermore, there was a positive correlation between inflammatory score and vascular TCC deposits $(t=8 \cdot 05 ; p<0 \cdot 001$. Table 1$)$.

In specimens from two UC patients we observed thrombosed submucosal blood vessels with TCC positivity both in the vessel wall and in the thrombus (Fig. 2). These arterioles were located beneath densely inflamed and damaged mucosa of patients who were severely ill when colectomy was performed.

Terminal complement complex deposits were detected on fibrillary elements (Fig. 3) in the muscularis mucosae or submucosa of five UC specimens (nos $4,6,7,8,9)$ and in one specimen from a

Table $3 T C C$ deposits in control specimens without inflammation

\begin{tabular}{llllll}
\hline $\begin{array}{l}\text { Patient } \\
\text { no }\end{array}$ & Age (yrs) & Sex & $\begin{array}{l}\text { Specimen } \\
\text { site }\end{array}$ & $\begin{array}{l}\text { Vascular } \\
\text { TCC }\end{array}$ & $\begin{array}{l}\text { Fibrillar } \\
\text { TCC }\end{array}$ \\
\hline 29 & 87 & F & Sigmoidium & $0 /(0$ & 0 \\
30 & 51 & M & Rectum & $0 / 0$ & 0 \\
31 & 57 & M & Sigmoidium & $0 / 0$ & 0 \\
32 & 64 & M & Sigmoidium & $0 / 0$ & 0 \\
33 & 56 & F & Rectum & $0 / 0$ & 0 \\
34 & 86 & M & Rectum & $0 / 0$ & 0 \\
35 & 78 & F & Sigmoidium & $++/+++$ & 0 \\
36 & 78 & F & Rectum & $0 / 0$ & 0 \\
37 & 70 & F & Rectum & $0 / 0$ & 0 \\
38 & 80 & F & Sigmoidium & $0 / 0$ & 0 \\
\hline
\end{tabular}

Table 2 Clinical information about patients with Crohn's disease in the ileum and TCC deposits in their ileal lesion

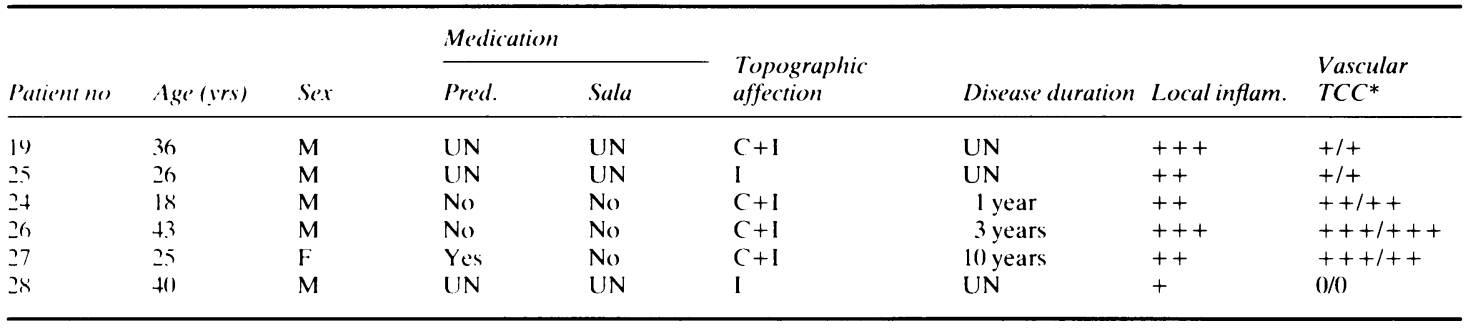

Pred. - - prednisolone: Sala. = salazopyrin: UN= unknown: $C=$ colon: $I=$ ileum. ${ }^{*}$ The vascular TCC score from two blind examinations. 


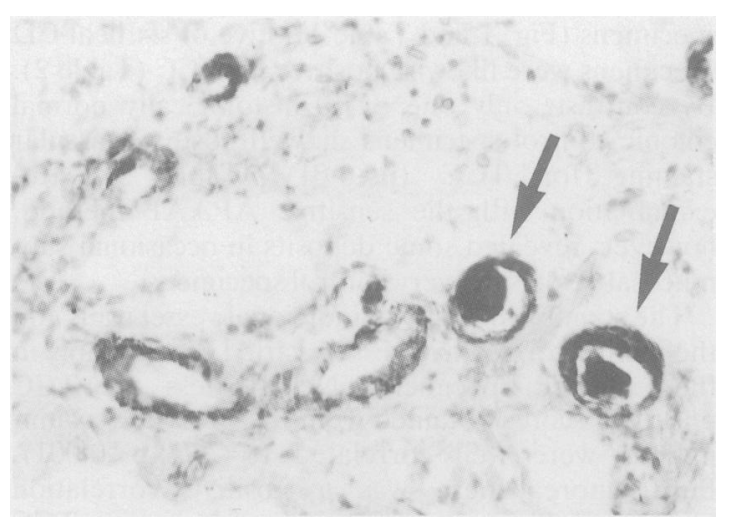

Fig. 2 Positive staining for TCC in a thrombosed submucosal vessel. Note TCC positivity both in the thrombus and in the vessel wall (arrows). APAAP staining on ethanolfixed paraffin-embedded colonic specimens counterstained with haematoxylin from UC patients No. 7. (Magnification $\times 10())$.

patient (no 18) with CD of the colon. Additional sections from these tissue blocks were re-examined and stained for elastin. The similarity of the staining patterns suggested that the TCC positivity was associated with the elastic fibrils. The majority of such fibrils, however, were TCC-negative. TCC-positive fibrils were not observed in histologically normal mucosa.

Germinal centres of secondary follicles from ileum (Peyer's patches) and colon was positively stained for TCC in a dendritic pattern. This staining feature was shown to be associated with the follicular dendritic cells and could be observed in histologically normal mucosa and other lymphoid tissues as well. ${ }^{1 .}$

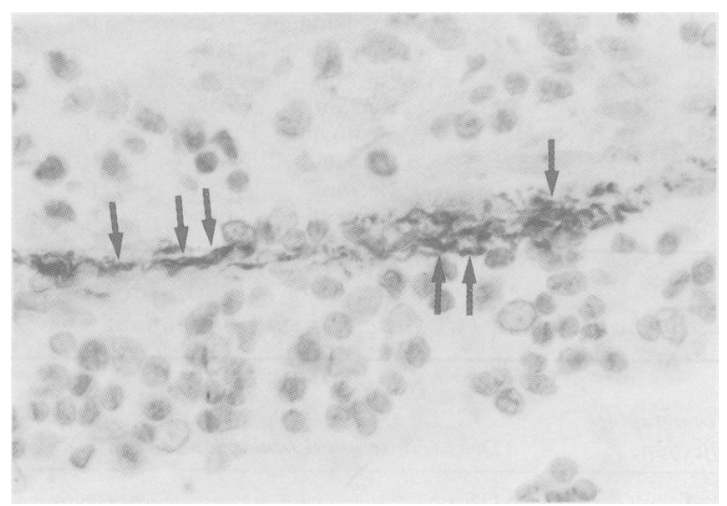

Fig. 3 TCC positivity on fibrillary elements in muscularis mucosae (arrows). Identical TCC positive fibrils were also observed in the submucosa. APAAP staining of washed, ethanol-fixed and paraffin-embedded colonic specimens. counterstained with haematoxylin from a patient with ulcerative colitis. (Magnification $\times 162$ ).

\section{Discussion}

The demonstration of substantially more TCC in colonic submucosal blood vessel walls in IBD than in histologically normal controls, is apparently a new observation of pathogenetic interest. There was no significant difference in vascular TCC deposits between UC and CD of the colon. The inflammatory lesions might in fact have contained more TCC than that observed, because we usually observed less vascular TCC positivity in paraffin blocks stored for more than 10 years. Eight of the UC, six of the colonic CD, and all the ileal CD blocks were older than 10 years, whereas none of the control blocks were older than six years.

The vascular TCC deposition should not be considered specific for IBD because trace amounts were seen in the controls, particularly with the sensitive APAAP method. Other workers have likewise observed immunohistochemical staining for TCC in arterioles and arteries in cryosections of normal human renal tissue ${ }^{16}$ and myocardium.'

Vascular complement deposits are often regarded as signs of a type III hypersensitivity reactions. Circulating immune complexes may become deposited in the vessel walls of inflamed areas. When rabbits with formalin induced rectal mucosal damage are injected intravenously with human serum albumin-anti-albumin immune complexes, the result is a severe colitis and crypt abscesses. ${ }^{1 *}$ Human endothelial cells have been shown to express receptors for $\mathrm{C} 3 \mathrm{~b}$ and $\mathrm{Fc}_{\gamma}$ in vitro when infected with herpes, ${ }^{19}$ cytomegalo- or influenza virus. ${ }^{21}$ Bovine pulmonary endothelial cells express such receptors in vitro when incubated with white cell lysate." It is unknown whether inflammation per se will induce such receptors, but their expression may explain why circulating immune complexes preferentially become deposited in blood vessel walls of inflamed areas. It is controversial, however, whether patients with IBD have raised levels of circulating immune complexes."

Other mechanisms could well be involved in the observed submucosal vascular TCC deposition. Locally produced IgG antibodies might complex with luminal antigens in situ and induce a local immune complex disease or Arthus type reaction as suggested by the presence of TCC-positive thrombosed submucosal blood vessels in two UC patients. Although vascular TCC deposits have been demonstrated in leucocytoclastic vasculitis of the skin,,$^{\prime 3}$ no cellular infiltrates or fibrinoid necrosis of the TCC-positive submucosal vascular walls were observed. The majority of our patients, however, received immunosuppressive medication which could have modified such reactions. 
Previous immunohistochemical studies of complement factors in IBD have been based on antisera which do not distinguish between native and activated components. Also, tissue specimens with unpredictable amounts of retained extracellular proteins have been used. It is therefore uncertain whether previously observed $\mathrm{Clq}^{24}$ and $\mathrm{C}^{24}{ }^{2+4}$ deposits in the intestinal epithelial basement membrane zone represented immune complexes or retained native components. ${ }^{25} \mathrm{Wc}$ used extensively washed tissue specimens from which extracellular diffusible proteins had been extracted; and our MoAb to a neocpitope of TCC reacted exclusively with terminal activated complement. We observed virtually no TCC positivity in the basement membrane zone.

Mucosal terminal complement activation may, however, take place in the fluid phase. Although soluble immune complexes may induce complement activation and extensive $\mathrm{C} 3$ consumption, relatively little soluble TCC (SC5b-9) is produced.$^{2 n}$ Furthermore, soluble SC5b-9 is most likely removed by our tissue washing procedure. We therefore believe that the vascular TCC was present in a tissue bound form and not as free soluble SC5b-9.

In addition to its well known biological effects, complement activation products such as $\mathrm{C} 3 \mathrm{a}$ and $\mathrm{C} 5 \mathrm{a}$ may trigger other biological systems that participate in the inflammatory reaction. $\mathrm{C} 3 \mathrm{~b}, \mathrm{iC} 3 \mathrm{~b}$, and $\mathrm{C} 3 \mathrm{c}$ have been shown to stimulate human macrophages to release prostaglandin $\mathrm{E}_{2}\left(\mathrm{PGE}_{2}\right),{ }^{2127}$ and $\mathrm{C} 3 \mathrm{a}$ and $\mathrm{C} 3 \mathrm{~b}$ induce thromboxane $\mathrm{B}_{2}\left(\mathrm{TXB}_{2}\right)$ release. ${ }^{.72 \mathrm{Cx}} \mathrm{C} 3 \mathrm{a}$, C5a, and C5 $\mathrm{a}_{\mathrm{des}} \mathrm{Arg}$ have been shown to stimulate the production of leucotriene $\mathrm{B}_{4}$ in guinea pig ileum and in lung tissue cultures. ${ }^{29}$ in Furthermore, generation of TCC on cell membranes have been shown to stimulate human macrophages to release $\mathrm{PGE}_{2}$ and $\mathrm{TXA}_{2}{ }^{3 .}$ Such TCC also induces the production of free oxygen radicals by cultured rat mesangial cells. ". The possibility therefore exist that the increased amounts of $\mathrm{TXB}_{2}$ and $\mathrm{PGE}_{2}$ produced in vitro by rectal mucosa from $\mathrm{UC}^{33}$ and the raised concentrations of the $\mathrm{PGE}_{2}$ and leukotriene $\mathrm{B}_{4}$ shown by in vivo equilibrium dialysis of rectum in relapsing UC, ${ }^{3}$ may have been induced by complement activation products. The TCC positive fibrillary elements observed in the muscularis mucosae and submucosa in five UC specimens and in one colonic CD specimen may have been associated with S-protein positive elastic fibrils as elastic fibres of human skin have been shown to stain for S-protein. ${ }^{35}$

In conclusion, our results suggested that in situ terminal complement activation takes place in the intestinal lesions of UC and CD. Regardless of the mode of complement activation and the nature of the target attacked, generation of biologically active products (C3a, C5a, and TCC) will cause inflammation. Local terminal complement activation may therefore be of pathogenetic importance in IBD.

This work was presented in part at the XVII annual meeting of the Scandinavian Society for Immunology, Tampere, Finland, June 1986, and was published as an abstract in Scand J Immunol 1986; 24: 463. TSH is a Research Fellow of the Norwegian Cancer Society.

\section{References}

1 MacKechnic HLN. The immunology of inflammatory bowel disease. Henry Ford Hosp Med J 1982; 30: 25-32.

2 Strober W, James SP. The immunologic basis of inflammatory bowel disease. J Clin Immunol 1986; 6: 415-32.

3 Baklien K. Brandtzacg P. Comparative mapping of the local distribution of immunoglobulin-containing cells in ulcerative colitis and Crohn's disease of the colon. Clin Exp Immunol 1975; 22: 197-209.

4 Kett K, Rognum TO, Brandtzacg P. Mucosal subclass distribution of immunoglobulin G-producing cells is different in ulcerative colitis and Crohn's disease of the colon. Gastroenterology 1987; 93: 919-24.

5 Chao LP. Steele J, Rodrigues C, et al. Specificity of antibodies secreted by hybridomas generated from activated $B$ cells in the mesenteric lymph nodes of patients with inflammatory bowel disease. Gut 1988; 29: 3.5-40.

6 Folkersen J, Söfeldt S, Svehag S-E. Application of electronblotting technique to studies of intestinal antibody response to extractable fecal antigens. Scand $J$ Gastroenterol 1985: 20: 247-53.

7 Monteiro E. Fossey J, Shiner M. Antibacterial antibodies in rectal and colonic mucosa in ulcerative colitis. Lancet 1971; i: 249-51.

8 Das KM, Sakamaki S, Vecchi, M, Diamond B. The production and characterization of monoclonal antibodies to human colonic antigen associated with ulcerative colitis: cellular localization of the antigen by using the monoclonal antibody. J Immunol 1987; 139: 77-84.

9 Ballard J, Shiner M. Evidence of cytotoxicity in ulcerative colitis from immunofluorescent staining of the rectal mucosa. Lancet 1974; i: 1014-7.

10 Bhakdi A, Tranum-Jensen J. Membrane damage by complement. Biochim Biophys Acta 1983; 737: 343-72.

11 Podack ER, Müller-Eberhard HJ. Isolation of human S-protein, an inhibitor of the membrane attack Complex of complement. J Biol Chem 1979; 254: 9908-14.

12 Brandtzaeg P. Mucosal and glandular distribution of immunoglobulin components. Immunohistochemistry with a cold ethanol-fixation technique. Immunology 1974; 26: 1101-14.

13 Mollnes TE, Lea T, Harboe M. Tschopp J. Monoclonal antibodies recognizing a neoantigen of poly(C9) detect the human terminal complement complex in tissue and plasma. Scand J Immunol 1985; 22: 183-95.

14 Brandtzacg P. Dale I, Fagerhol M. Distribution of a formalin-resistant myclomonocytic antigen (L1) in human tissues. I. Comparison with other leukocyte 
markers by paired immunofluorescence and immunoenzyme staining. Am J Clin Pathol 1987; 87: 681-99.

15 Halstensen TS, Mollnes TE, Brandtzaeg P. Terminal complement complex (TCC) and S-protein (vitronectin) on follicular dendritic cells in human lymphoid tissues. Immunology 1988; 65: 193-7.

16 Falk RJ, Podack E, Dalmasso AP. Jennette JC. Localization of S-protein and its relationship to the membrane attack complex of complement in renal tissue. Am J Pathol 1987; 127: 182-90.

17 Schäfer H, Mathey D, Hugo F, Bhakdi S. Deposition of the terminal C5b-9 complement complex in infarcted areas of human myocardium. J Immunol 1986; 137: 1945-9.

18 Hodgson HJF, Potter BJ, Skinner J, Jewell DP. Immune-complex mediated colitis in rabbits. An experimental model. Gut 1978; 19: 225-32.

19 Cines DB, Lyss AP. Bina M, Corkey R, Kefalides NA. Friedman HM. Fc and C3 receptors induced by herpes simplex virus on cultured human endothelial cells. J Clin Invest 1982; 69: 123-8.

20 Ryan US, Schultz DR, Ryan JW. Fc and C3b receptors on pulmonary endothelial cells: induction by injury. Science 1981; 214: 557-8.

21 Rutherford B, Schenkein HA. C3 clevage products stimulate release of prostaglandins by human mononuclear phagocytes in vitro. J Immunol 1983; 130: 874-7.

22 Danis VA, Harries AD, Heatley RV. Antigen-antibody complexes in inflammatory bowel disease. Scand $J$ Gastroenterol 1984; 19: 603-6.

23 Boom BW, Out-Luiting CJ, Baldwin WM, Westedt M-L, Daha MR, Vermeer B-J. Membrane attack complex of complement in leukocytoclastic vasculitis of the skin. Presence and possible pathogenetic role. Arch Dermatol 1987; 123: 1192-5.

24 Otto HF, Gebbers JO. The local immune response in ulcerative colitis. Pathol Res Pract 1979; 165: 349-64.

25 Baklien K. Brandtzacg P. Immunohistochemical localization of complement in intestinal mucosa. Lancet 1974; ii: $1087-8$.

26 Bhakdi S, Fassbender W, Hugo F, Berstecher C,
Malasit P. Careno MP, Kazatchine M. Relative inefficiency of terminal complement activation in the fluid phase [Abstract]. Complement 1987; 4: 1.34-5.

27 Hartung HP. Hadding U, Bitter-Suermann D, Gemsa D. Stimulation of prostaglandin $E$ and thromboxane synthesis in macrophages by purificd C3b. J Immunol 1983; 130: 2861-5.

28 Hartung HP. Bitter-Sucrmann D. Hadding U. Induction of thromboxane release from macrophages by anaphylatoxic peptide C3a of complement and synthetic hexapeptide C3a 72-77. J Immunol 1983; 130: 134.5-9.

29 Stimler NP. Bach MK. Bloor CM. Hugli TE. Release of leucotrienes from guinea pig lung stimulated by C.5 $\mathrm{a}_{\text {des Arg }}$ anaphylatoxin. J Immunol 1982; 128: 224752.

30) Pison U, Kunau WH, Damerau B, König W. Induction of leukotriene formation by anaphylatoxins C.a and C5a [Abstract]. Immunobiology 1983; 164: 265.

31 Hänsch GM, Seitz M, Martinotti G, Betz M, Rauterberg EW, Gemsa D. Macrophages release arachidonic acid, prostaglandin $\mathrm{E}$, and thromboxanc in response to late complement components. J Immunol 1984; 133: 2145-50.

32 Adler S, Baker PJ, Johnson RJ, Ochi RF, Pritzl P. Couser WG. Complement membrane attack complex stimulates production of reactive oxygen metabolites by cultured rat mesangial cells. J Clin Invest 1986; 77: $762-7$.

33 Ligumsky M, Karmeli F, Sharon P, Uriel Z, Fortunc C', Rachmilewitz D. Enhanced thromboxane A2 and prostacyclin production by cultured rectal mucosa in ulcerative colitis and its inhibition by steroids and sulfasalazine. Gastroenterology 1981; 81: 444-9.

34 Lauritsen K, Laursen LS, Bukhave K, Rask-Madsen J. Effects of topical 5-aminosalicylic acid and prednisolone on prostaglandin E2 and leukotriene B4 levels determined by equilibrium in vivo dialysis of rectum in relapsing ulcerative colitis. Gastroenterology 1986; 91: 837-44.

35 Dahlbäck K, Lofberg H, Dahlbäck B. Localization of vitronectin (S-protein of complement) in normal human skin. Acta Dermatol Venereol 1986; 66: 461-7. 